\title{
Obesity in junk food generation in Asia: A health time bomb that needs early defusing!
}

\author{
Sayeeda Rahman ${ }^{1,2}$ \\ ${ }^{1}$ Lecturer, Department of Clinical Sciences, School of Medical Sciences, University of Bradford, West Yorkshire, Bradford, UK. \\ ${ }^{2}$ Associate Editor, South East Asia Journal of Public Health, Bangladesh.
}

One of the most profound results of globalization has been the rapid rise in the number of western-style fast food outlets around the world, and the trend is sharply rising in Asian countries. ${ }^{1,2}$ In parallel with the increasing consumption of fast food, obesity and obesityrelated diseases are also rising. ${ }^{3}$ Obesity has now been identified as a major cause of disability and premature deaths in less developed countries. This has been attributed mainly to shifts in diet and lifestyle changes. ${ }^{3}$ The South East Asia and Western Pacific regions are currently facing an epidemic of diseases associated with obesity such as diabetes and cardiovascular diseases (CVD). ${ }^{2,3}$ India has the highest number of people with diabetes in the world and China occupies the second position. ${ }^{5}$ It has been estimated that obesity accounts for $2 \%$ to $7 \%$ of total healthcare costs. ${ }^{6}$ There are also other costs to consider such as reduced quality of life and productivity loss attributed to medical leave. ${ }^{6}$ The World Health Organization itself describes an escalating global epidemic of overweight and obesity - 'globesity' - that is taking over many parts of the world and warned that: 'If immediate action is not taken, millions will suffer from an array of serious health disorders'?

In this issue, a paper examined the fast food consumption among graduate students in Bangladesh. ${ }^{8}$ The findings are alarming as young adolescents are becoming addicted to fast food. It has been identified that fast food consumers usually young adults and educated than nonfast food consumers. Due to aggressive marketing, fast food is becoming very popular with adolescents, who are at a stage in life in which they experience increased autonomy. ${ }^{3}$ Other factors which influence consumption and purchasing decisions among adolescents include taste preferences, convenience, and food availability and value. ${ }^{7}$ Studies in India ${ }^{9}$, Singapore ${ }^{10}$, China ${ }^{11}$, Malaysia $^{12}$ and other Asian countries ${ }^{13}$ had shown a rising prevalence of obesity among children and adolescents.

Fast food is calorically dense, typically features meat and processed meat, highly refined carbohydrates, is generally high in sodium and cholesterol, and has a poor dietary fatty acid profile. ${ }^{1,4}$ Processed meats increase the risk of type 2 diabetes and coronary heart disease (CHD); red meat, high fat dairy as protein sources and high sodium content are linked to greater risk of CHD; and the glycemic properties of fried potatoes and processed grains could increase risk of diabetes and CHD. ${ }^{1,3}$
Moreover, decreasing dietary fiber intake may also contribute to cardio-metabolic risk. Fast food consumption is also positively associated with energy intake and soft drink consumption, and negatively associated with fruit, vegetable and milk intakes in adolescents. ${ }^{14}$ Limited studies have directly examined western-style fast food with health risks in Asia; this is because fast food intake in east and south-east Asia only started becoming somewhat prominent in the late 80 's and early 90 's. ${ }^{1}$

A recent study examined the association of westernstyle fast food intake with risk of incident type 2 diabetes and CHD mortality in Asian context. ${ }^{1}$ The investigators used data from the Singapore Chinese Health Study, which included more than 43,000 Chinese adults in Singapore and followed them for 5 years. They found that people who consumed fast food even as little as once a week, increased their risk of developing coronary heart disease by $20 \%$ compared to those who never touched it. The rate jumped to $50 \%$ for those who indulged 2-3 times/week, and to $80 \%$ for those who went beyond that. Regular consumption of fast food also seemed to lead to a substantially higher risk of type 2 diabetes. The study has a number of strengths, including the large sample size, high-quality follow-up data, and prospective design. $^{3}$

There are several possible mechanisms for increased risk of cardio-metabolic outcomes associated with frequent fast food intake. Fast foods may contribute to central obesity, insulin resistance, and elevated blood pressure. $^{1,3,14}$ In Asia countries, governments have not yet seriously considered regulations that would limit or ban the use of partially hydrogenated oils, making fast food a major contributor to intake of trans fat. ${ }^{3}$ Many fast foods are high in calories, which may lead to overeating and excess calorie intake. ${ }^{15}$ In addition, the portion sizes at many fast-food outlets have increased by 25 fold over the past several decades. ${ }^{16}$ Many Asian countries are undergoing rapid economic and social change, resulting in radical shifts in dietary patterns and lifestyle habits. ${ }^{1,3}$ Traditional dietary patterns, characterized by high intake of vegetables and whole grains and limited consumption of animal products, are shifting towards western dietary patterns. All these issues will have serious consequences on health of the population and will stretch limited resources available for healthcare.

Correspondence: Dr. Sayeeda Rahman, Lecturer, Department of Clinical Sciences, School of Medical Sciences, University of Bradford, Bradford BD7 1DP, West Yorkshire, UK. E-mail: srahman6@bradford.ac.uk.

South East Asia Journal of Public Health 2013;3(1):1-2. C 2013. Rahman, publisher and licensee Public Health Foundation Bangladesh. This is an Open Access article which permits unrestricted non-commercial use, provided the original work is properly cited. 
Multiple strategies are needed to curb the epidemic of obesity among adolescents, especially in relation to fast food and soft drinks. Country specific and culturally relevant studies should be conducted to understand the influences over consumption which may assist in developing interventions to replace fast food with more nutritious food and drinks. Changing the food environment to limit the availability of soft drink in the home and at school, and increasing the cost of nutrient poor foods relative to nutrient rich food items would seem useful strategies. Similarly, policies to restrict the expansion of fast food outlets, especially around educational institutes, ban on aggressive advertisement of fast food, encouraging outlets to provide healthy options at competitive prices, and encourage physical activities that are targeted at young people may also prove effective strategies.

\section{References}

1. Odegaard AO, Koh WP, Yuan JM, Gross MD, Pereira MA. Western-style fast food intake and cardiometabolic risk in an Eastern country. Circulation 2012;126(2):182-8.

2. Tabassum A, Rahman T. Differences in consumer attitude towards selective fast food restaurants in Bangladesh: An implication of multiattribute attitude model. World Rev Bus Res 2012;2(3):12-27.

3. Pan A, Malik VS, Hu FB. Exporting diabetes mellitus to Asia: the impact of Western-style fast food. Circulation 2012;126(2):163-5.

4. Pereira MA, Kartashov AI, Ebbeling CB, Van Horn L, Slattery ML, Jacobs DR Jr, Ludwig DS. Fast-food habits, weight gain, and insulin resistance (the CARDIA study): 15-year prospective analysis. Lancet 2005;365:36-42.

5. International Diabetes Federation. Diabetes Atlas. 4th edition. Belgium: International Diabetes Federation, 2009.

6. World Health Organization. Report of a joint WHO/FAO Expert. Consultation. Diet, nutrition and the prevention of chronic diseases. WHO technical report series No. 916. Geneva: World
Health Organization, 2003.

7. World Health Organization. Controlling the global obesity epidemic. http://www.who.int/ nutrition/topics/obesity/en/ (accessed July 2013)

8. Bipasha MS, Goon S. Fast food preference and food habits among students of private universities in Bangladesh. South East J Public Health 2013; 3(1):61-64.

9. Ramachandran A, Snehalatha C, Vinitha R, Thayyil M, Kumar CK, Sheeba L, et al. Prevalence of overweight in urban Indian adolescent school children. Diabetes Res Clin Pract 2002;57(3):185-90.

10. Chia M, Wang J, Sock-Miang TK, Quek JJ, Kumar K. Relationship between hours of computer use, physical activity and physical fitness among children and adolescents. Eur J Phys Educ 2002;7(2):136-55.

11. Li Y, Zhai F, Yang X, Schouten EG, Hu X, He Y, Luan D, Ma G. Determinants of childhood overweight and obesity in China. $\mathrm{Br} J \mathrm{Nutr}$ 2007;97(1):210-5.

12. Sidik SM, Ahmad R. Childhood obesity: contributing factors, consequences and intervention. Malaysian J Nutr 2004;10(1):13-22.

13. Parizkova J, Chin MK, Chia M, Yang J. An international perspective on obesity, health and physical activity: current trends and challenges in China and Asia. J Exerc Sci Fitness 2007;5 (1):7-23.

14. French SA, Story M, Neumark-Sztainer D, Fulkerson JA, Hannan P. Fast food restaurant use among adolescents: associations with nutrient intake, food choices and behavioural and psychosocial variables. Int J Obes 2001;25:182333.

15. Prentice AM, Jebb SA. Fast foods, energy density and obesity: A possible mechanistic link. Obes Rev 2003; 4:187-4.

16. Nielsen SJ, Popkin BM. Patterns and trends in food portion sizes, 1977-1998. JAMA 2003;289:450-3. 